\title{
Nanochemistry - A Split between 18th Century and Modern Times
}

\author{
P. Heinzerling ${ }^{*}$, M. Oetken \\ Department of Chemistry, University of Education Freiburg, Kunzenweg 21, D-79117 Freiburg, Germany \\ *Corresponding author: peter.heinzerling@web.de
}

\begin{abstract}
Nanoscience seems to be a main topic of this century. The chemical fundamentals are very old and named colloids since Graham in 1861. The acronym nano has been introduced in 1960 at a conference of measures and weights in Paris. In 1982 Binnig and Rohrer invented the scanning tunnel microscope(STM) and four years later Binnig the atomic force microscope(AFM). These microscopes are the main tools for the nanotechnology and from this times the number of publications exploded. In this article we'll focus on the chemical aspects of nanotechnology and how to implement experiments into school.
\end{abstract}

Keywords: nanochemistry, history, colloids, fundamental reaction principles, experiments

Cite This Article: P. Heinzerling, and M. Oetken, "Nanochemistry - A Split between 18th Century and Modern Times.” World Journal of Chemical Education, vol. 6, no. 1 (2018): 1-7. doi: 10.12691/wjce-6-1-1.

\section{Introduction}

At what time chemical nanotechnology did start? That's a good question. There are very old products from China with nanodimensions like chinese ink - produced by topdown-method from charcoal. In medieval times glass technologists from Florence were able to produce colorful glasses by mixing with gold, silver and copper. These two examples were under contemporary criteria nanoproducts, but mainly the glass production was more alchemy than science. Wolfgang Ostwald - eldest son of the nobel price winner Wilhelm Ostwald - held speeches in the US from 1913 to 1914 and published them under the title ,The World of neglected Dimensions“ [1]. This was the beginning of systematic colloidal chemistry. He started a research department at University of Leipzig in 1923 and researchers from all over the world came to participate. They could do very instructive experiments without analytical tools for the synthesized products. His book, Practical Colloid Chemistry، from 1924 - a standard for practical training at German universities - is a historic source for a lot of experiments which can be implemented into school [2].

\section{Fundamentals}

Chemical nanotechnology consists in producing materials different from typical macroscopic properties by fundamental reaction principles. E.g. bulk materials like gold with their typical physical properties like color, melting point differ in a fundamental manner from gold nanoparticles. Synthetic methods are not really different from typical reactions:

- redox-reactions give nanoscalic metals or nonmetals
- acid-base-reactions to produce e.g. ferrofluid

- complex-reactions

Surfaces can be coated by nanomaterials to get functionalized subsumed as sol-gel-chemistry. This chemistry operates with so-called precursors which reacts on the surface in mostly condensation-reactions. The representative chemistry is based on TEOS (tetraethylorthosilicate) and other metal-organic alcoxides. Other methods are reacting directly with the material based on chemical reaction between typical functional groups - e.g. OH-groups at the surface of ceramics and fabrics.

\section{History}

In 1857 Faraday produced during one of his famous Bakerial Lectures a red colored gold dispersion by reducing gold chloride-solution with white phosporous [3]. He detected the gold particles by light scattering - the first tool of nanotechnology was born. Later on Tyndall could show that the scattered light beam was polarized [4] and this can be demonstrated today with a laser pointer and diluted milk (Figure 1).
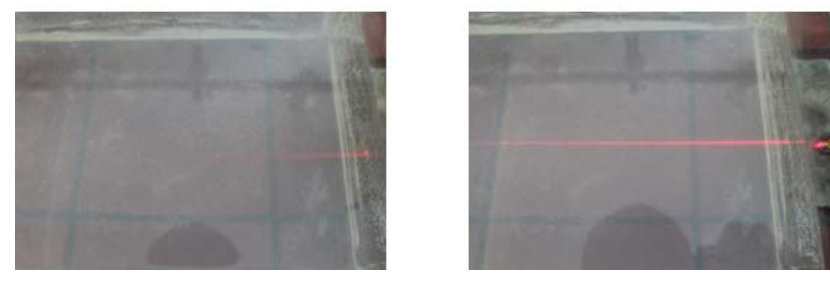

Figure 1. Faraday-Tyndall effect: polarization in diluted milk

Towards the end of this century and the beginning of the 20th we find a lot of publications concerning colloids. In this article we'll focus on the synthesis of metallic 
particles and the so-called sol-gel-chemistry. For a long time nobody could show the very small particles. Siedentopf and Zsigmondy used an ultramicroscope for detecting the gold particles in the gold ruby glass in 1902 [5]. For his researches concerning the colloidal gold Zsigmondy did win the Nobel Price in 1925. His results about the dimensions of gold particles were far away from the reality. The era of modern microscopes began in 1932 with the transmission electron microscope (TEM) [5], followed by the scanning electron microscope (SEM) [6] and ended in the 1980s with the scanning tunnel microscope (STM) [7] and the atomic forces microscope (AFM) [8]. Mainly with the last tools one could manipulate nanoparticles. The laser backscattering method gives exact results of the dimensions.

The first industrial application of sol-gel-chemistry was introduced in 1939 by the german glassmaker Schott to produce an antireflective surface [9]. During his speeches in the US Ostwald demonstrated a very instructive experi ment with Prussian Blue. Using saturated solutions of iron(III) chloride and potassium hexacyanoferrate(III) he obtained a gel (Figure 2).

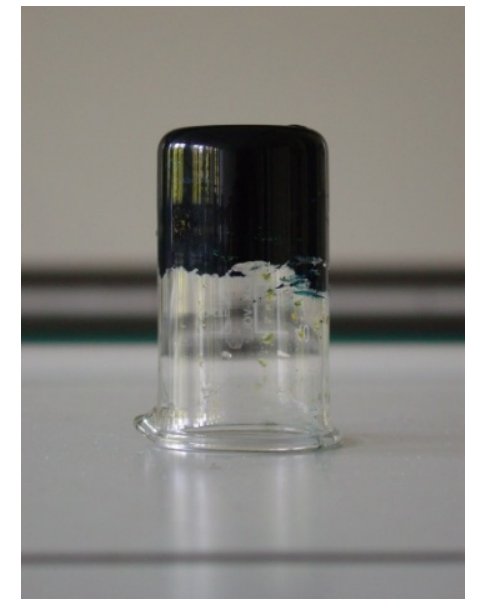

Figure 2. Gel from saturated Prussian Blue

Stirring a very small amount of the gel into a large volume of water one could see nothing. Using a focussed light beam the particles of Prussian Blue could be shown by the Faraday-Tyndall-effect. The sol-gel-chemistry did wake up at the end of the 1980s [10]. This chemistry is still very active in consumer products.

\section{Nanochemistry Based on Redox-reactions}

Nanoparticles of metals can be synthesized from highly diluted solution of their cations. The most attractive examples are gold and silver with colorful results. The theoretical background of the formation of micro-particles is the so-called Ostwald-ripening explaining the formation of the crystals [11]. Historic experiments show very instructive reactions. Donau from Graz (Austria) reduced solutions of gold(III)chloride and other metal-ions with cold CO [12] and burning hydrogen [13]. These old experiments can be adapted as contemporary micro-scale. Other classical reductions are connected with the names of Turkevich [14] and Creighton [15].

\subsection{Gold(III)-reduction with Carbon Monoxide}

\section{Experimental:}

Instruments: Micro Gas burner (Propane), green laser pointer

Chemicals: solution of $10^{-3} \mathrm{M} \mathrm{HAu(III)Cl} \mathrm{Cl}_{4}$

The gold(III)-solution is filled into a 25 ml-beaker and the burning propane must be held with the reducing zone into the solution. Within 30 seconds the redviolet color of nanoscale gold particles will appear. The size of these particles is about $100 \mathrm{~nm}$.

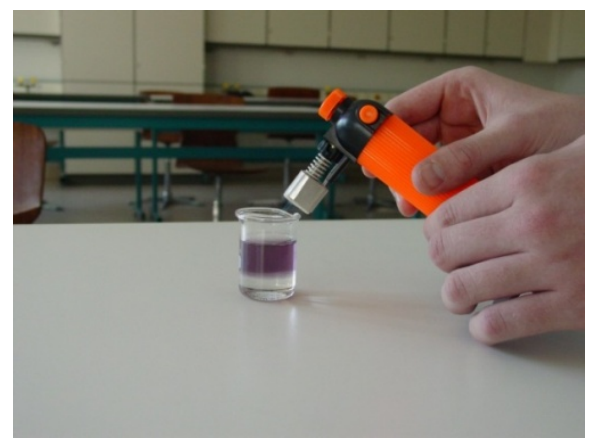

Figure 3. Reducing of gold(III)-ions with a propane burner

The particles can be shown as Faraday-Tyndall-effect with the laser pointer.

The origin experiment of Donau used cold Carbon monoxide prepared from oxalate and the reduction needed hours.

\subsection{Gold(III)-reduction with Burning Hydrogen}

\section{Experimental:}

Instruments: medical hollow needle $160 \mathrm{~mm}$, silicone tube green laser pointer

Chemicals: solution of $10^{-3} \mathrm{M} \mathrm{HAu(III)Cl}{ }_{4}$, HydrogenMinican $®$ (Linde), copper-wire (explosion protection for the needle)

The gold(III)-solution is filled into a 25 ml-beaker. Hydrogen is streaming through the medical hollow needle and ignited. The flame should get a size of $3 \mathrm{~cm}$ and will be held on the surface of the gold(III)-solution. Within 30 seconds the red-violet color of nanoscale gold particles will appear.

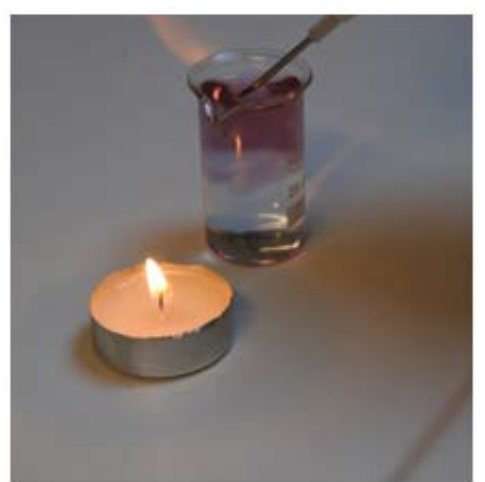

Figure 4. Reducing of gold(III)chloride-solution with burning hydrogen. The candle-light was used to ignite the hydrogen. 
The particles can be shown as Faraday-Tyndall-effect with the laser pointer.

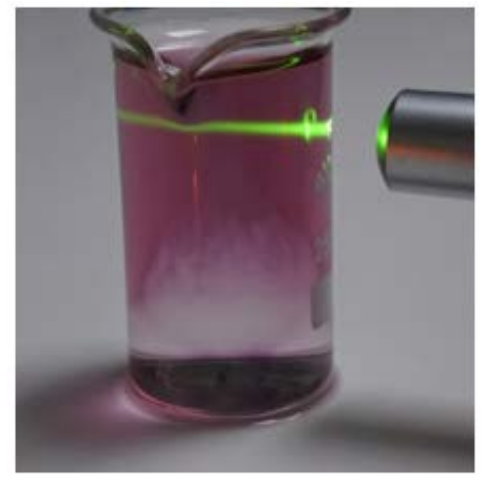

Figure 5. Detection of gold-nanoparticles by Faraday-Tyndall-effect

By the same method nanoparticles of silver and molybdenum blue can be produced.
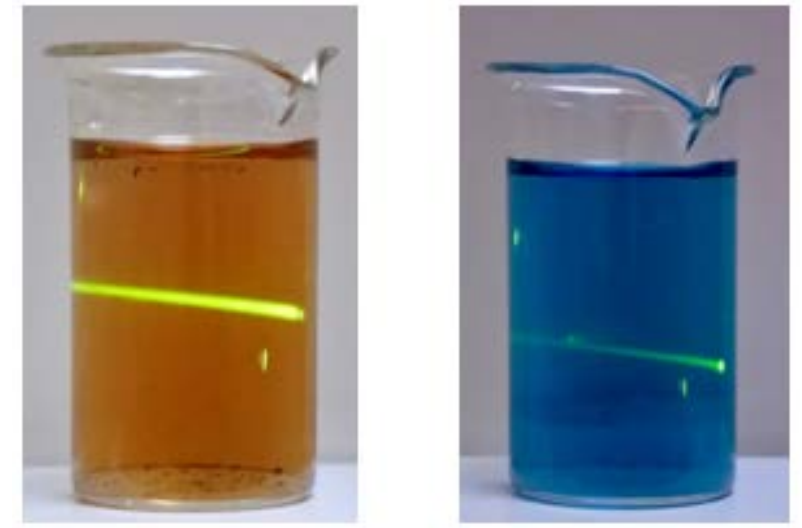

Figure 6. Left side: silver-nanoparticles, right side: molybdenum bluenanoparticles

The origin experiment of Donau used a large glass lance. Under the pressure of the burning hydrogen the formation of nitrous oxides as reducing agents has been discussed [16].

\subsection{Reductions with Citrate}

In modern literature the method of Turkevic is the standard for the synthesis of gold-nanoparticles [14]. The citrate-ion is reducing and capping agent. The mechanism can be explained by an organic reaction:

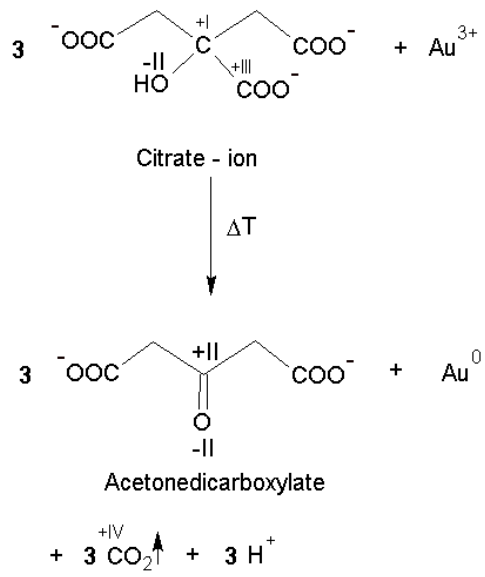

An electrochemical reduction-potential of $-0.180 \mathrm{~V}$ is cited but not proved [17].

Because of kinetic inhibition of the citrate the Turkevicreaction must be executed in a boiling solution. We used a version with a household microwave oven giving results within minutes.

\section{Experimental:}

Instruments: Household Microwave Oven 800 W, PP pipet

Chemicals: solution of $10^{-3} \mathrm{M} \mathrm{HAu(III)Cl}{ }_{4} \cdot 3 \mathrm{H}_{2} \mathrm{O}$, Sodium citrate $(\mathrm{w}=1 \%)$

$30 \mathrm{ml}$ of the $\mathrm{HAu}(\mathrm{III}) \mathrm{Cl}_{4}$ solution is filled into a $300 \mathrm{ml}$ Erlenmeyer-flask. $3 \mathrm{ml}$ of the citrate-solution is given to the solution and the flask is placed into the microwave oven. The oven is regulated to $360 \mathrm{~W}$ and the mixture is heated for three minutes. The experiment can be operated in the same way with a $10^{-3} \mathrm{M}$ silver nitrate-solution.

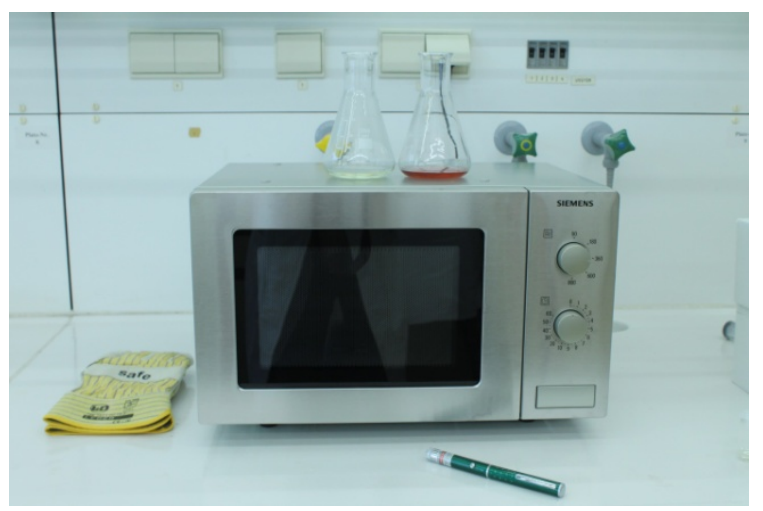

Figure 7. Reduction by Turkevic-method in a microwave oven

Left side: pale yellow silver nanoparticles, right side: rubinred gold nanoparticles

Silver nitrate can be reduced with a microspatula portion of bulk sodium citrate too.

\subsection{Nano goes Green: Reduction of Gold(III)ions with Antioxydanses}

There are many natural sources for reducing agents. Polyphenols like tannins, flavins and catechins will be found in coffee [18], teas [19] and flowers [20], tannin in red wine.

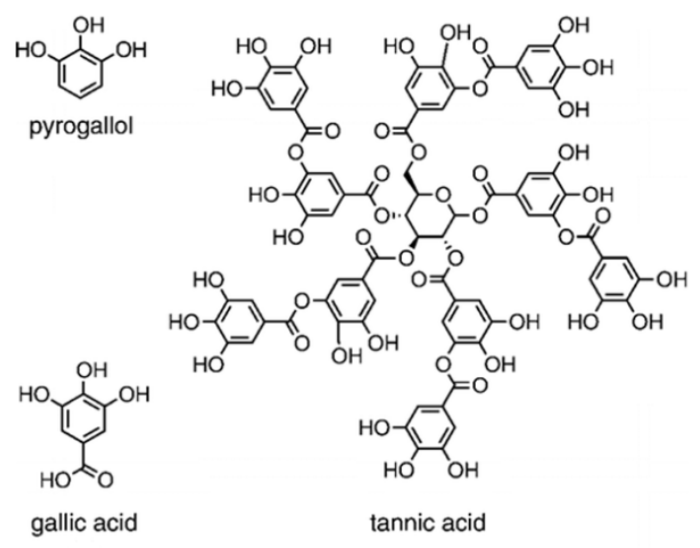

Figure 8. Tannins in tea-leafs [21] (Reprinted with Permission of American Chemical Society) 
<smiles>Oc1cc(O)c2c(c1)O[C@H](c1ccc(O)c(O)c1)[C@H](O)C2</smiles>
(EC)<smiles>O=C(O[Ga]O[C@H]1Cc2c(O)cc(O)cc2O[C@@H]1c1ccc(O)c(O)c1)c1cc(O)c(O)c(O)c1</smiles>
(ECG)<smiles>O=C(O)c1cc(O)cc2c1C[C@H](O)[C@H](c1cc(O)c(O)c(O)c1)O2</smiles>

$(\mathrm{EGC})$
Figure 9. Catechins in tea leafs [21] (Reprinted with Permission of American Chemical Society)

These phenolic groups are strong reducing agents. There are experiments to reduce gold, silver and palladium with extracts of teas.

\section{Experimental:}

Instrumental: red laser pointer, PP dropping pipet, electric heater and stirrer

Chemicals: $10^{-3} \mathrm{M} \mathrm{HAuCl}_{4} \cdot 3 \mathrm{H}_{2} \mathrm{O}$, cold extract of green tea leafs, dry red wine

To reduce the tetrachloro auric(III) acid give the extract of green tea leafs - 1 teaspoon in $250 \mathrm{ml}$ cold $\mathrm{H}_{2} \mathrm{O}$ for 5 minutes - dropwise into $25 \mathrm{ml}$ of the gold(III)-solution until a color change occurs.

The reducing with tannins give the red wine dropwise to a boiling solution of tetrachloro auric(III) acid until the red colored colloids occurs.

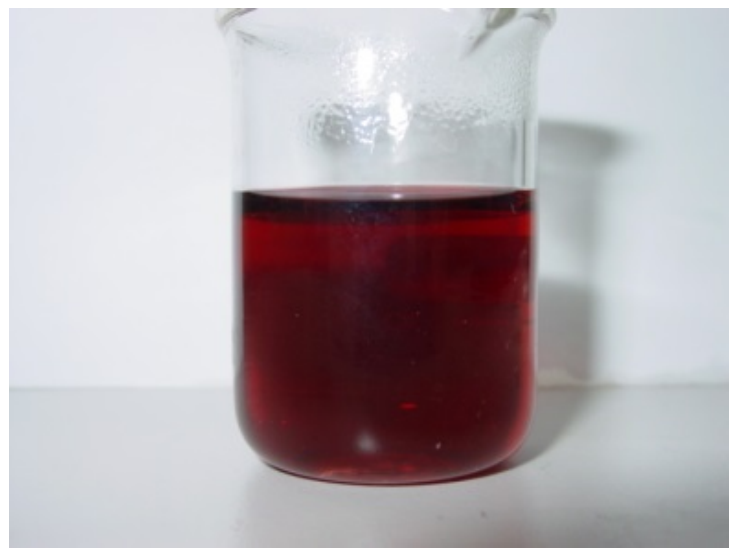

Figure 10. Gold nano colloids prepared from $10^{-3} \mathrm{M} \mathrm{HAuCl}_{4} \cdot 3 \mathrm{H}_{2} \mathrm{O}$ and dry red wine

The gold nanoparticles are indicated with the red laser pointer by the Faraday-Tyndall effect.

\subsection{Silver(I)-reduction with Boron hydride}

Creighton published a method of preparing $12 \mathrm{~nm}$ Silver-nanoparticles with an ice-cold solution of Sodium boron hydride [22]. The result is a pale-yellow dispersion. The Boron hydride-ions are very strong capping agent with stability over months and years.

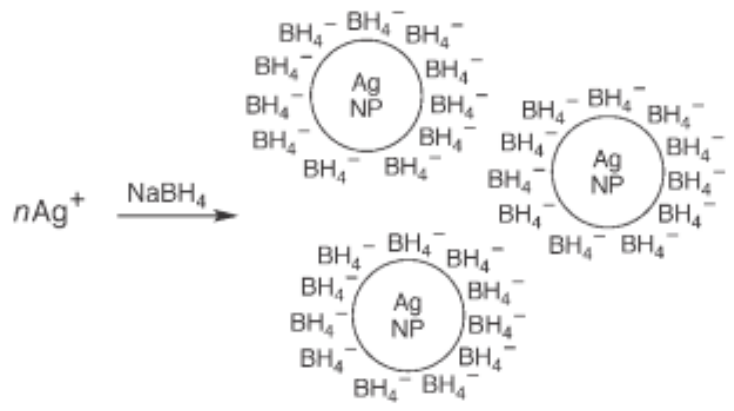

Figure 11. Boron hydride-ions as capping agent

\section{Experimental:}

Instrumental: green laser pointer, electromagnetic stirrer

Chemicals: $10^{-3} \mathrm{M} \mathrm{AgNO}_{3}, 2 \cdot 10^{-3} \mathrm{M} \mathrm{NaBH}_{4} 10 \mathrm{ml} 30$ $\mathrm{ml} 10^{-3} \mathrm{M} \mathrm{AgNO}_{3}$ is dropped under stirring into ice-cold $2 \cdot 10^{-3} \mathrm{M} \mathrm{NaBH}_{4}$. The pale-yellow silver-nanoparticles are from a diameter of $12 \mathrm{~nm}$ detected by the laser pointer.

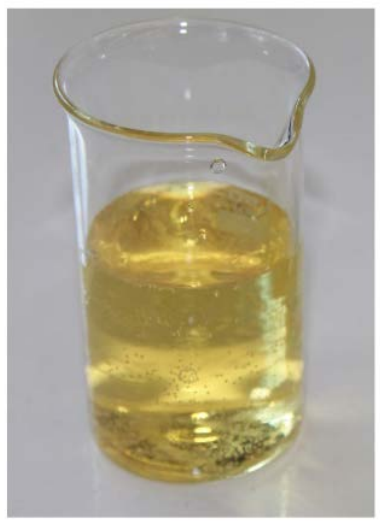

Figure 12. Silver-Nanoparticles from Creighton-method

\subsection{Copper(II)-reduction with Ascorbic Acid}

Copper-Nanoparticles are the main ingredients of environmental-friendly antifouling paintings.

In a simple experiment we can produce this particles by the reduction of copper(II)ions with ascorbic acid.

\section{Experimental:}

Instrumental: red laser pointer

Chemicals: $\mathrm{CuSO}_{4} \cdot 5 \mathrm{H}_{2} \mathrm{O}$ (s), Ascorbic acid (s) (drugstore)

Two spoons of $\mathrm{CuSO}_{4} \cdot 5 \mathrm{H}_{2} \mathrm{O}$ (s) and ascorbic acid (s) are mixed together with $10 \mathrm{ml}$ of deionized water. The suspension will be shaked well for half a minute. The color is changing from blue to green and the coppernanoparticles are detected by the laser pointer.

There are two steps within the reaction:

Table 1. Reduction potentials of copper-ions

\begin{tabular}{|c|c|}
\hline Half-reaction & Reduction potential (V) \\
\hline $\mathrm{Cu}^{2+}(\mathrm{aq})+\mathrm{e} \rightarrow \mathrm{Cu}^{+}(\mathrm{aq})$ & 0,17 \\
\hline $\mathrm{Cu}^{+}(\mathrm{aq})+\mathrm{e} \rightarrow \mathrm{Cu}(\mathrm{aq})$ & 0,52 \\
\hline
\end{tabular}

To get a successful first step, the $\mathrm{pH}$ must be lower than $0,17 \mathrm{~V}$. In the table the $\mathrm{pH}$-dependency of the reduction potential of the ascorbic acid is listed: 
Table 2. pH-dependency of the reduction potential of ascorbic acid

\begin{tabular}{|c|c|}
\hline $\mathrm{pH}$ & Reduction potential (V) \\
\hline 3,3 & 0,200 \\
\hline 4,0 & 0,166 \\
\hline 5,0 & 0,127 \\
\hline 7,0 & 0,060 \\
\hline
\end{tabular}

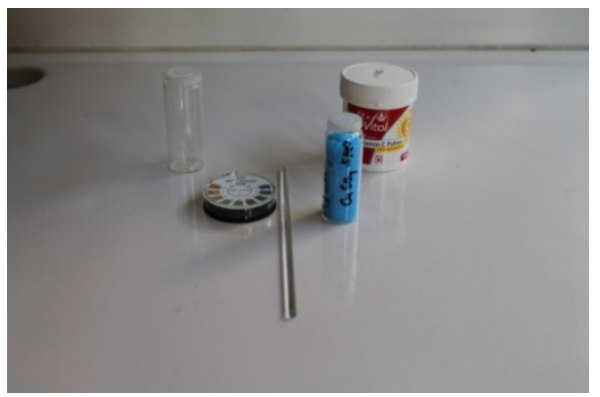

Figure 13. Instrumental and chemicals

The $\mathrm{pH}$ should be controlled with an indicator paper.

After some hours the copper particles will precipitate.

\section{Nanochemistry based on Acid-Base- Reaction}

Ferrofluid is the nanoscale material of the iron ore magnetite. It can be produce top-down by treatment with a ball mill. In the chemical laboratory the main method consists in the bottom-up synthesis by the reaction between iron(II)- and iron(II)chloride in an alkaline medium.

The result is a superparamagnetic dispersion. To get the real ferrofluid the iron(II,III)oxide has to be suspended in heptane or light gasoline. The newest applications are in the medical sector [23]. Ferrofluid is used in the imaging of magnetic resonance examinations. It can be doped with cytostatics and transported via arteria by a strong magnet to the cancer cells.

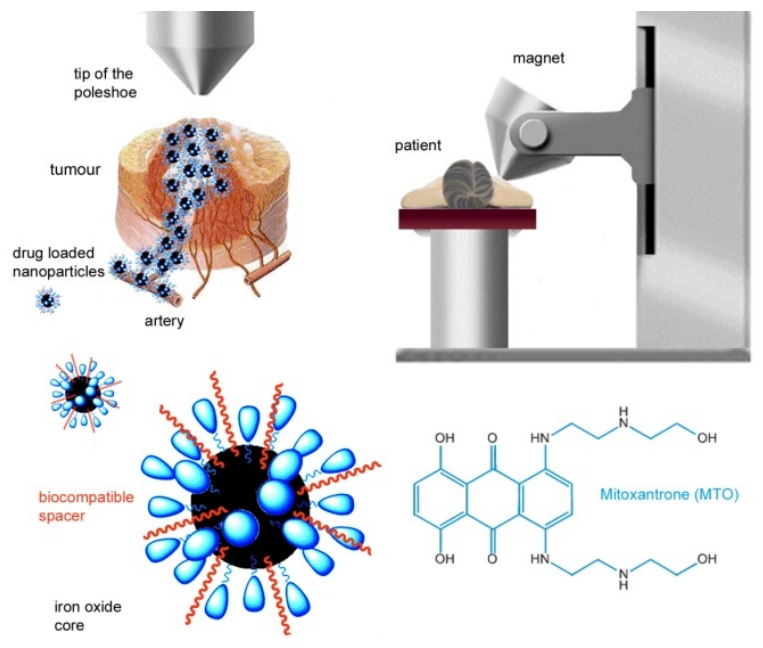

Figure 14. Treatment of cancer with ferrofluidic doped cytostatics (Source: [24]) @ MDPI AG (Basel)

Another method has been developed for the treatment of gliobastomes: The ferrofluid is docking at the cancer cells und they are heated by an external alternate current field.

\section{Experimental:}

Instrumental: beaker, pipets, electromagnetic stirrer, neodyme magnet, gloves

\section{Chemicals:}

$3 \mathrm{M}$ Iron(II)chloride in $2 \mathrm{M} \mathrm{HCl}, 1 \mathrm{M}$ Iron(III)chloride in $2 \mathrm{M} \mathrm{HCl}, 0,7 \mathrm{M}$ Ammonia

This experiment has to be executed under a hood [25].

$2 \mathrm{ml}$ of the Iron(II)chloride in $2 \mathrm{M} \mathrm{HCl}$ and $1 \mathrm{ml}$ of the $1 \mathrm{M}$ Iron(III)chloride in $2 \mathrm{M} \mathrm{HCl}$ are mixed and vigorously stirred. $50 \mathrm{ml} \mathrm{0,7} \mathrm{M}$ Ammonia will be dropped to this mixture.

With a neodyme magnet the suspended iron(II,III)oxide can be shown in the beaker.

The so called Rosenzweig hedgehog [26] can be shown with ferrofluid:

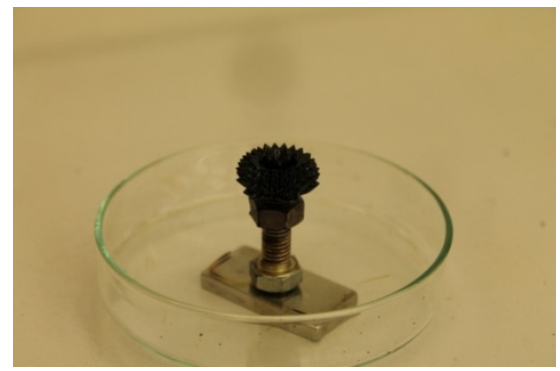

Figure 15. Rosenzweig hedgehod with superparamagnetic ferrofluid

The ferrofluid is commercially available via Ebay.

\section{Sol-Gel-Chemistry}

Metal alkoxides in an alcoholic medium can be hydrolysed resulting in a condensation reaction resulting oxygen-bridged compounds. These compounds can be transferred to a surface giving the material new properties. The alcoholic solution of the metal alkoxides consists in a sol.

Dipping the material into the sol we'll get on the surface a gel from evaporating of the alcohole.
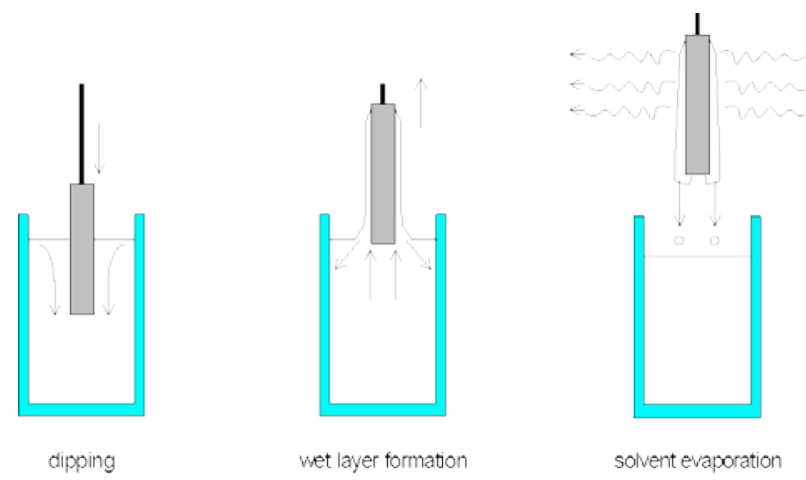

Figure 16. Sol-gel coating by dipping (Source: http://www.solgel.com/articles/nov00/mennig.htm)

The chemical reaction is similar to a polycondensation resulting in a clustered compound (e,g, Silicon alkoxide):

$\mathrm{Si}(\mathrm{OR})_{4}$
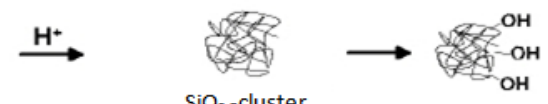
The free hydroxyl-groups can be functionalised e.g. by fluorinated compounds.

To achieve a stable surface the material has to be calcinated at temperatures of about $200^{\circ} \mathrm{C}$.

\section{Experimental:}

Instrumental: low-cost dipping machine made from a grill-machine
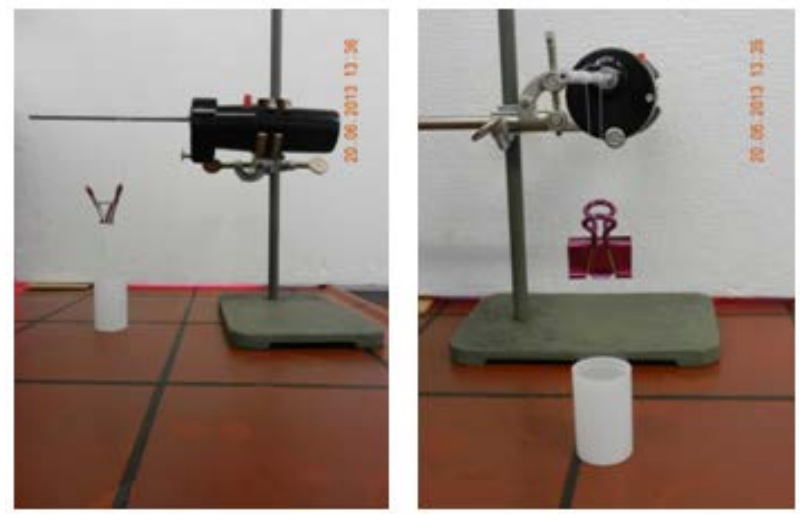

Figure 17. low-cost dipping machine

\section{Chemicals:}

Tetraethyl orthosilicate (TEOS) (30 vol\%), 2-propanol (65 vol\%), $3 \mathrm{M} \mathrm{HNO}_{3}$ (5 vol\%)

A microscope slide as substrate is dipped into the TEOS-solution and the substrate is swinging in the air until the alcohol is evaporated. The surface will be a thin film of antireflective glass. A treatment with fluoroorganic compounds will result in superhydrophobic or oleophobic properties.

The first application of treatment of glass with TEOS were multifocal lenses from plastics. After treatment the surface will be scratch resistant and anti-reflective.

\section{Nano meets Consumers}

There are many other applications of chemical nanotechnology, some of them used in fabrics.

Fabrics from cotton are of good reactivity because of the free $\mathrm{OH}$-groups from the cellulose.

They react very fast with chloro silanes resulting in and two- to three-dimensional structure:

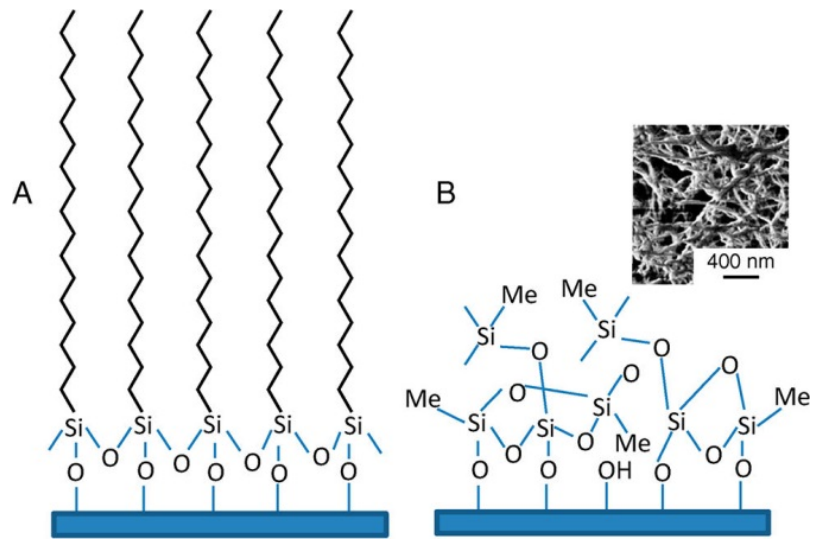

Figure 18. Reaction of choro silanes on a glass surface (From [27] with permission of the American Chemical Society)

\section{Experimental:}

Instrumental: centrifuge tube, $1 \mathrm{ml}$ medical syringe, Tesafilm ${ }^{\circledR}$, gloves

\section{Chemicals:}

trichloro methylsilane, dichloro octadecylsilane

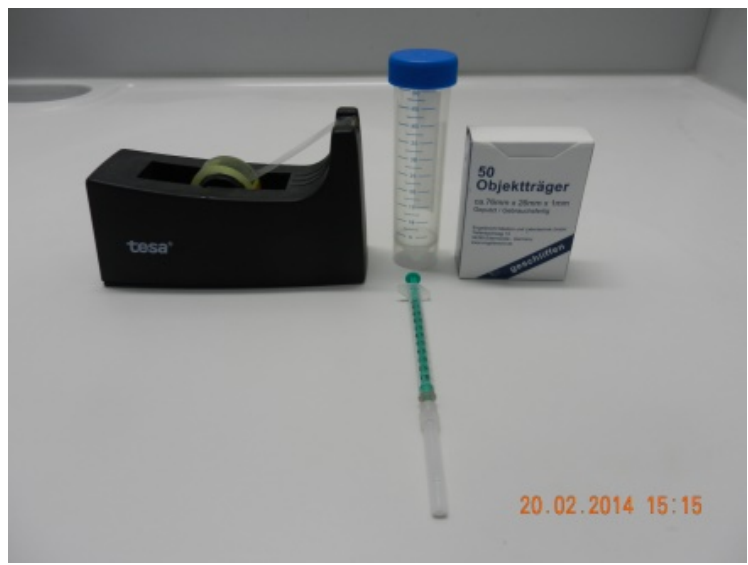

Figure 19. Experiment with glass slides

One drop of the chloro silane will be transferred into the tube. Then the substrate (cellulose diaper, cotton, glass slide) is placed into the tube. After screwing the tube the reaction will occure within five minutes. The glass slide is covered partially with Tesafilm ${ }^{\circledR}$ to get treated and untreated surfaces.

During this condensation reaction hydrochloric acid will be eliminated. So you have to wear gloves and the experiment should take place in a well ventilated hood.

The material is superhydrophobic und this can be demonstrated with a small drop of water. The contact angle was measured with the freeware ImageJ.
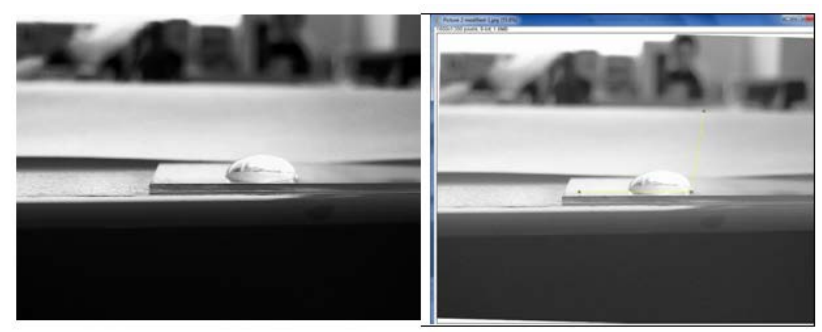

Figure 20. Left: water droplet on a glass surface; Right: determination of the contact angle $>90^{\circ}$ (yellow lines) with Image J

Eva Preiß from Friedrich-Alexander-University Erlangen-Nuremberg, Department of Material Sciences, made pictures from the surfaces by AFM. After treatment with trichloro methylsilane the surface of the glass was coated with buds of up to $100 \mathrm{~nm}$. This is in accordance with the theory from Wenzel resp. Cassie-Baxter concerning the super hydrophobic properties of surfaces.

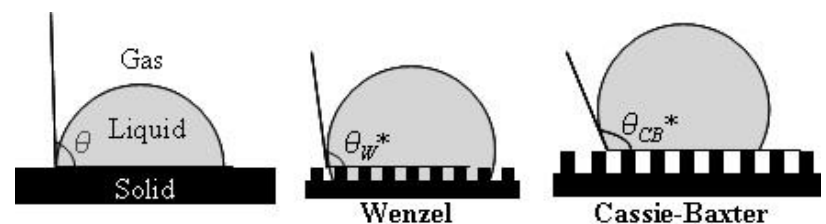

Figure 21. Theories of super hydrophobic properties of surfaces [28] 

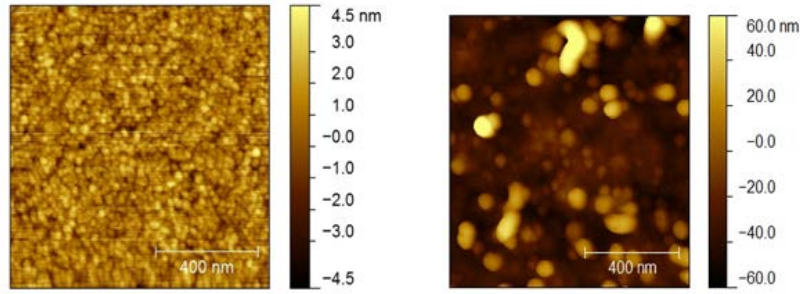

Before treatment

After treatment

Figure 22. Pictures of atomic forces microscopy (AFM) from coated glass (Pictures: E. Preiß)

\section{Summary and Outlook}

The history of nanoparticles is very old. Systematic researches began with the publications of Wolfgang Ostwald in the 1920s. The main tools of the nanotechnology were developed by Binnig and Rohrer in the 1980s and they were awarded with the nobel prize in 1986. The study of very old sources leads to experiments which can be done in high school and college chemistry labs. In this article there is a choice of selected experiments. Meanwhile the number of publications of experiment in this level exploded within the last ten years.

By the way: The abrevation nano exists since the $11^{\text {th }}$ International Conference of Measures and Weights in 1960 [29]. Up to this date it was named by Ostwald millimicro $(\mathrm{m} \mu)[1]$.

\section{Acknoledgements}

P.H. was funded by the cluster of excellence Engineering of Advanced Materials (EAM) at FriedrichAlexander-University Erlangen-Nuremberg.

\section{References}

[1] W. Ostwald, An Introduction to Theoretical and Applied Colloid Chemistry, "The World of Neglected Dimensions,” Wiley, 1917.

[2] W. Ostwald, Practical Colloid Chemistry, Methuen And Company Limited, 1926.

[3] M. Faraday, The Bakerian Lecture: Experimental Relations of Gold (and Other Metals) to Light, Philos. Trans. R. Soc. Lond., 147 (1857) 145-181.

[4] J. Tyndall, On the Blue Colour of the Sky, the Polarization of Skylight, and on the Polarization of Light by Cloudy Matter Generally, Proc. R. Soc. Lond., 17 (1868) 223-233.

[5] M. Knoll, E. Ruska, Das Elektronenmikroskop, Z. Für Phys., 78 (1932) 318-339.

[6] M. von Ardenne, B. von Borries, Electron scanning microscope, US2241432 A, 1941.

[7] G. Binnig, H. Rohrer, C. Gerber, E. Weibel, Tunneling through a controllable vacuum gap, Appl. Phys. Lett., 40 (1982) 178-180.

[8] G. Binnig, C.F. Quate, C. Gerber, Atomic Force Microscope, Phys. Rev. Lett., 56 (1986) 930-933.
[9] P. Berger, N.B. Adelman, K.J. Beckman, D.J. Campbell, A.B. Ellis, G.C. Lisensky, Preparation and Properties of an Aqueous Ferrofluid, J. Chem. Educ., 76 (1999) 943.

[10] H. Schmidt, Considerations about the sol-gel process: From the classical sol-gel route to advanced chemical nanotechnologies, J. Sol-Gel Sci. Technol., 40 (2006) 115.

[11] W. Ostwald, Über die vermeintliche Isomerie des roten und gelben Quecksilberoxyds und die Oberflächenspannung fester Körper, Z. Für Phys. Chem., 34 (1900) 495-503.

[12] J. Donau, Ueber eine rote, mittels Kohlenoxyd erhaltene kolloidale Goldlösung, Monatshefte Für Chem. Verwandte Teile Anderer Wiss., 26 (1905) 525-530.

[13] J. Donau, Ueber die Bildung kolloider Lösungen mittelst Flammen oder elektrischer Entladungsfunken, Kolloid-Z., 16 (1915) 81.

[14] J. Turkevich, P.C. Stevenson, J. Hillier, A study of the nucleation and growth processes in the synthesis of colloidal gold, Discuss. Faraday Soc., 11 (1951) 55-75.

[15] J.A. Creighton, C.G. Blatchford, M.G. Albrecht, Plasma resonance enhancement of Raman scattering by pyridine adsorbed on silver or gold sol particles of size comparable to the excitation wavelength, J. Chem. Soc. Faraday Trans. 2 Mol. Chem. Phys., 75 (1979) 790-798.

[16] W. Halle, E. Pribram, Chemische und physikalisch-chemische Beobachtungen bei der Herstellung kolloider Goldlösungen, Berichte Dtsch. Chem. Ges., 47 (1914) 1398-1401.

[17] A. van Hoonacker, P. Englebienne, Revisiting Silver Nanoparticle Chemical Synthesis and Stability by Optical Spectroscopy, Curr. Nanosci., 2 (2006) 359-371.

[18] M. N. Nadagouda, R. S. Varma, Green synthesis of silver and palladium nanoparticles at room temperature using coffee and tea extract, Green Chem., 10 (2008) 859-862.

[19] S. K. Nune, N. Chanda, R. Shukla, K. Katti, R. R. Kulkarni, S. Thilakavathy, S. Mekapothula, R. Kannan, K. V. Katti, Green nanotechnology from tea: phytochemicals in tea as building blocks for production of biocompatible gold nanoparticles, J. Mater. Chem., 19 (2009) 2912-2920.

[20] N. von Weimarn, Versuche zur Herstellung leicht reproduzierbarer Goldsole von rein roter Farbe mit wässerigen Auszügen aus Blumen, Kolloid-Z., 44 (1928) 41-42.

[21] G. Panzarasa, K. Sparnacci, Glowing Teacup Demonstration: Trautz-Schorigin Reaction of Natural Polyphenols, J. Chem. Educ., 89 (2012) 1297-1300.

[22] J.A. Creighton, C.G. Blatchford, M.G. Albrecht, Plasma resonance enhancement of Raman scattering by pyridine adsorbed on silver or gold sol particles of size comparable to the excitation wavelength, J. Chem. Soc. Faraday Trans. 2 Mol. Chem. Phys., 75 (1979) 790-798.

[23] I. Torres-Díaz, C. Rinaldi, Recent progress in ferrofluids research: novel applications of magnetically controllable and tunable fluids, Soft Matter, 10 (2014) 8584-8602.

[24] C. Janko, S. Dürr, L.E. Munoz, S. Lyer, R. Chaurio, R. Tietze, S. von Löhneysen, C. Schorn, M. Herrmann, C. Alexiou, Magnetic Drug Targeting Reduces the Chemotherapeutic Burden on Circulating Leukocytes, Int. J. Mol. Sci., 14 (2013) 7341-7355.

[25] P. Berger, N.B. Adelman, K.J. Beckman, D.J. Campbell, A.B. Ellis, G.C. Lisensky, Preparation and Properties of an Aqueous Ferrofluid, J. Chem. Educ., 76 (1999) 943.

[26] M.D. Cowley, R.E. Rosensweig, The interfacial stability of a ferromagnetic fluid, J. Fluid Mech., 30 (1967) 671-688.

[27] J.X.H. Wong, H.-Z. Yu, Preparation of Transparent Superhydrophobic Glass Slides: Demonstration of Surface Chemistry Characteristics, J. Chem. Educ., 90 (2013) 1203-1206.

[28] A.B.D. Cassie, S. Baxter, Wettability of porous surfaces, Trans. Faraday Soc., 40 (1944) 546-551.

[29] Bureau International Poids et Mesures, BIPM - Resolution 12 of the 11th CGPM, (1960). 